\title{
El derecho de sufragio de personas extranjeras: de la tradición exclusionista a la desnacionalización de los derechos. Una mirada desde el derecho comparado
}

Foreign persons right to vote: From the exclusionist tradition to the denationalization of rights. A view from comparative law

\author{
Karla Elizabeth Andrade Quevedo \\ Universidad Internacional SEK
}

\section{Resumen}

En la actualidad, el reconocimiento de derechos políticos a personas extranjeras ha recibido cierta apertura Europa y Latinoamérica; no obstante, la visión marshalliana ${ }^{1}$ de ciudadanía no ha sido superada y la nacionalidad permanece como el elemento condicionante para el reconocimiento pleno del derecho de sufragio. El mundo globalizado exige que el Estado evolucione, dejando de lado los miedos y paranoias del pasado, para permitir la universalización del sufragio, la obtención de una verdadera democracia representativa y la plena legitimación democrática. Este artículo analiza el derecho de sufragio de personas extranjeras desde la tradición exclusionista clásica hasta la integración de extranjeros a través de la desnacionalización de los derechos políticos, para a partir de ahí contrastar las distintas posturas y alcances que le han dado varios países de Europa y América Latina.

\section{Palabras clave}

Derecho de sufragio / Extranjeros / Derecho comparado.

\section{Summary}

Recognition of political rights for foreigners has received certain openness in Europe and Latin America; however, the Marshallian view of citizenship has not been overcome and nationality remains as the determining factor for full recognition of the right to vote. This globalized world requires State's evolution, leaving fears and paranoia behind to permit universal suffrage, real representative democracy, and full democratic legitimation. This article analyzes foreigners' right to vote from the classic exclusionist tradition to the full integration of foreigners through the denationalization of political rights; from there it contrasts the different postures and scopes that numerous countries form Europe and Latin America have given to this right.

\section{Keywords}

Right to vote / Foreigners / Comparative Law.

\section{Introducción}

Si miramos atrás, la historia demuestra que los derechos de participación política han sido un catálogo de privilegios. Ya en la antigua Grecia la participación en la vida pública del

\footnotetext{
${ }^{1}$ En 1950, T.H. Marshall definió la ciudadanía como "aquel estatus que se concede a los miembros de pleno derecho de una comunidad, donde sus beneficiarios son iguales en cuanto a los derechos y obligaciones que implica” (Marshall, 2007, Pg. 37).
} 
Estado estaba reservada únicamente a un grupo reducido de ciudadanos. Desde entonces, la humanidad ha recorrido un largo camino de incansable lucha por la democratización de los derechos políticos. Se han eliminado requisitos como propiedad, edad, religión o género; sin embargo, la nacionalidad persiste como el requisito que mantiene a las personas extranjeras excluidas del más emblemático derecho político: el derecho de sufragio.

En el mundo moderno, la exclusión de los derechos de participación política a los extranjeros se remonta al siglo XVIII cuando la Declaración de Derechos del Hombre y el Ciudadano consolidó las bases de diferenciación entre hombre y ciudadano. El extranjero pasó a gozar de derechos civiles, como persona, pero fue excluido de la vida política del Estado, pues ese derecho se materializó como un derecho exclusivo de los ciudadanos. Con ello, los conceptos de nacionalidad y ciudadanía se han mezclado hasta confundirse.

El auge del Estado-Nación endureció la exclusión de personas extranjeras de los derechos políticos. Los sentimientos nacionalistas se vieron representados en las constituciones liberales y aquello provocó la nacionalización de los derechos. Prácticamente durante todo el siglo XIX y XX existió una sólida oposición al reconocimiento de derechos políticos a los inmigrantes (Aja y Moya, 2008).

A finales del siglo XX se produjo una disociación entre nacionalidad y ciudadanía que permitió la ampliación del catálogo de derechos de personas extranjeras. El fortalecimiento del Estado liberal y la expansión de los derechos humanos abrieron la puerta para el reconocimiento de derechos políticos como los de asociación, reunión y manifestación. Además, a partir de 1970, países del norte de Europa empezaron a hablar de la necesidad de reconocer este derecho al colectivo extranjero y se convirtieron en los pioneros de su reconocimiento en el ámbito local.

Los tratados internacionales y los organismos supranacionales han aportado también a la ampliación del catálogo de derechos de personas extranjeras. No obstante, no han contribuido al desarrollo de los derechos políticos. En su mayoría los tratados internacionales reconocen la potestad exclusiva del Estado para regularlos; tienden a hablar de ciudadanos; y permiten incluso su restricción cuando ésta esté justificada dentro de parámetros de objetividad y razonabilidad.

Sin perjuicio de aquello, la creación de la ciudadanía europea, en 1992, constituye un importante giro para el derecho de sufragio de extranjeros. El Tratado de Maastricht provocó reformas en los ordenamientos jurídicos internos de los países miembros, permitiendo el sufragio activo y pasivo de los extranjeros comunitarios en ámbito local. Sin embargo, el reconocimiento de este derecho se dio, primordialmente, para cumplir las directrices de la Unión Europea, con lo cual no ha evolucionado más allá.

A día de hoy, la nacionalidad constituye el único impedimento para el reconocimiento pleno del derecho de sufragio activo y pasivo. La concepción de que los derechos políticos se conceden sólo a los miembros de pleno derecho de una comunidad no ha sido superada y sigue siendo la justificación a una limitación innecesaria que impide a los miembros reales de un Estado participar en la vida pública y ser parte del proceso democrático de la sociedad en la que viven. Otros factores como la residencia o permanencia estable en un territorio parecen vínculos más reales para otorgar estos derechos.

Como se verá en este artículo, su reconocimiento a personas extranjeras presenta posturas y alcances muy diversos, aunque todos muy limitados. En su mayoría, los Estados que han otorgado este derecho lo han hecho en el ámbito local y para el sufragio activo; y sólo de forma muy excepcional se lo ha ampliado al sufragio pasivo y al ámbito nacional. 


\section{Fundamentación clásica de la exclusión de personas extranjeras de los derechos políticos}

El Estado-Nación se caracterizó por la homogenización de la comunidad en virtud de rasgos culturales e históricos, por lo que solamente los nacionales compartían sentimientos de apego y fidelidad hacia el Estado. La exclusión del extranjero se convirtió en un mecanismo para garantizar que no se destruya esta unidad y homogeneidad, pues éste carecía de los medios idóneos para tener una adecuada percepción de la realidad política del país y sentir apego real por éste (Aja y Moya, 2008). Debido a su sumisión y dependencia a otro Estado, las personas extranjeras constituían una amenaza inminente para los intereses del Estado. Así, la exclusión era necesaria para evitar que los potenciales enemigos minen los componentes del Estadonación. En esta línea, Schmitt consideraba que "de otro modo se destruiría la comunidad y la unidad política, y desaparecería la condición esencial de la existencia política; la posibilidad de distinguir en entre el amigo y el enemigo" (Schmitt, 1992, p. 174).

A esto se sumó la soberanía, vista como independencia y negación a cualquier subordinación o limitación de un poder ajeno al Estado. Si la soberanía reside en el pueblo integrado únicamente por nacionales, entonces solamente a ellos les corresponde participar en la toma de decisiones. Para ello, el ejercicio de los derechos de participación política debe ser un privilegio exclusivo de los ciudadanos. De reconocérseles la categoría de elector a los extranjeros, estos pasarían a ser representantes y coautores de la soberanía popular, lo cual, bajo esta premisa, no es factible. Las personas extranjeras, por ser súbitos de otro Estado, padecen subordinación únicamente a su patria y por ende su participación política constituye una injerencia en la independencia del Estado. El voto constituye el instrumento de mayor poder que tienen las personas para incidir en las decisiones que afectan a toda la sociedad y la entrega de este poder a los extranjeros, es visto como una clara afectación a la soberanía y a la seguridad del Estado (Lozano, 1991).

Así, la doctrina más tradicionalista sostiene que la única vía para acceder al goce de los derechos políticos es a través de la nacionalización. Las personas extranjeras deben permanecer excluidas del derecho de sufragio hasta que obtengan la nacionalidad del Estado en el que residen. Sólo cuando pasan a ser súbditos del Estado adquieren todos los derechos como cualquier otro ciudadano, pues así conforma, formalmente, el pueblo soberano (Solanes, 2008).

\section{Desnacionalización del derecho de sufragio}

Las sociedades contemporáneas están atravesando profundos cambios, especialmente debido a los intensos movimientos migratorios de las últimas décadas. Por lo que, mantener el concepto marshalliano de ciudadanía, que excluye a los extranjeros del derecho de sufragio sacrifica principios importantes como la integración, igualdad, cohesión social y la universalización de los derechos. Por ello, existen una serie de fuertes argumentos que respaldan el otorgamiento de los derechos políticos a personas extranjeras.

El más antiguo y que ha sido la bandera de lucha a través de los siglos, es el de la universalización del sufragio para lograr la máxima aproximación del pueblo gobernado al pueblo que gobierna (Presno, 2011). Con la inclusión de nuevos actores, como las personas extranjeras residentes, se lograría una mayor aproximación del verdadero pueblo gobernado y, por consiguiente, una mejora cualitativa y cuantitativa de legitimidad de las decisiones adoptadas dentro del sistema político democrático.

Según la Carta Democrática Interamericana son elementos esenciales de democracia representativa, entre otros, "el respeto a los derechos humanos y las libertades fundamentales; 
el acceso al poder y su ejercicio con sujeción al estado de derecho; la celebración de elecciones periódicas, libres, justas y basadas en el sufragio universal y secreto como expresión de la soberanía del pueblo [...]" (Asamblea General de la Organización de Estados Americanos, 2001). Por consiguiente, su objetivo último es que los miembros reales de la sociedad tomen parte en la elección de sus representantes y en la elaboración de las normas y de la política gubernamental.

Pero cuando el conjunto de participantes en las decisiones públicas no coincide con el conjunto afectados por ellas, aparecen grandes deficiencias de legitimidad democrática. Autores como Kelsen, han afirmado que "el pueblo como conjunto de los titulares de la participación política representa, aún en democracia radical, sólo un pequeño sector de la totalidad de los sometidos a la ordenación política" (Kelsen, 1977). En la actualidad, la población de hecho no coincide realmente con la población de derecho y eso reduce la legitimidad democrática el Estado. No puede hablarse de una verdadera legitimidad de las autoridades públicas que se eligen a través del sufragio si éste no representa el demos real. Por lo tanto, desde la óptica de la legitimación democrática del sistema, los residentes extranjeros deberían tener la posibilidad de intervenir en la creación y modificación del ordenamiento jurídico al que están sometidos. Sólo así desaparecería la diferencia entre ciudadanos de primera y de segunda generación (denizens); o lo que es lo mismo, entre personas que deciden y personas que únicamente soportan las decisiones (Rubio-Marín, 2000).

En rigor, un modelo de democracia representativa exige poder participar en la formulación de las decisiones en el ámbito de la vida pública y especialmente en aquellas áreas que afectan derechos y obligaciones de forma inmediata (educación, salud, vivienda, tributos). De lo contrario, esto provoca que una proporción sustancial de personas que están sujetos al Estado, no tengan una verdadera representación local, regional ni nacional que defienda y garantice sus derechos e intereses. Por ende, los nacionales están asumiendo la cuota de representación que les corresponde a los extranjeros y esto va en contra del principio de que la democracia representativa nos impide decidir por otro (Santolaya y Revenga, 2007).

La única forma de maximizar el principio democrático y de legitimidad del Estado es permitir la participación en el ejercicio del poder a todo sujeto que esté sometido al mismo de forma estable, brindándole una conexión y cercanía con la autoridad. Es una exigencia de la propia definición del principio democrático que todos quienes se encuentran subordinados permanentemente a un ordenamiento jurídico deben tener la posibilidad de participar de forma libre, igual y plural. Por consiguiente, lo correcto es que todos aquellos que residen establemente en un Estado democrático sean considerados miembros de la comunidad política y que factores como la residencia estable y permanente en el territorio brinden el reconocimiento pleno de derechos político-participativos, pues sólo eso permitirá garantizar los pilares estructurales de los Estados actuales. La democracia representativa y liberal exige construir un demos que incluya a todos aquellos individuos sujetos, de forma permanente, a la autoridad del Estado, más allá de cualquier consideración respecto a su filiación o dependencia a otro Estado ${ }^{2}$. Habermas señala que:

Los derechos políticos son principios constituyentes valiosos en sí mismos y merecen reconocimiento, puesto que sin su concurso no puede un ordenamiento merecer obediencia. Sólo sobre la base de la participación pueden los extranjeros experimentar el convencimiento de que, obedeciendo leyes, se obedecen a sí mismos (Habermas, 2010, pg. 141).

2 La temporalidad constituye un factor a ser definido por cada Estado, no obstante, como se verá más adelante, el tiempo de residencia habitualmente oscila entre los 2 y 5 años. 
Este planteamiento es muy importante pues sólo la participación política puede integrar y corresponsabilizar al extranjero de las decisiones y los planes para el bien común de la sociedad. Permitir su participación, intensificaría su interés por la actividad pública y la política, se generaría una integración real y se garantizaría el ejercicio pleno de sus derechos. Al no ser parte del grupo que influye en la creación de la voluntad general, no se identifica con las normas y decisiones adoptadas, éstas no necesariamente responden a sus intereses y por ende no puede ejercer sus derechos a plenitud. Sólo la plena participación de todos los individuos que conforman la sociedad asegura la legitimidad y efectividad de las decisiones y el respeto por los derechos humanos. Sobre este aspecto, la Corte IDH ha determinado que "el ejercicio efectivo de los derechos políticos constituye un fin en sí mismo y, a la vez, un medio fundamental que las sociedades democráticas tienen para garantizar los demás derechos humanos previstos en la Convención" (CIDH, Castañeda Gutman vs. Estados Unidos Mexicanos, párr. 143).

\section{El derecho de sufragio de los extranjeros como mecanismo de integración}

Tradicionalmente, la integración de los extranjeros era vista como "asimilación"; es decir, como adaptación a la uniformidad cultural del país de acogida. Así, la integración se encontraba condicionada a la consecución de su mimetización respecto de la mayoría, pues con ello se evitaba la pérdida de la homogeneidad y la estabilidad de la sociedad de acogida (De Lucas, 1994). Esto, constituía una especie de clonación, puesto que su objetivo último era lograr que los inmigrantes abandonen sus orígenes y se conviertan en ciudadanos de la sociedad de acogida (Massó, 1997).

Actualmente, en cambio, la integración es entendida como un proceso de inserción y de equiparación de derechos en la diferencia. Es decir, la sociedad de acogida debe procurar la promoción de las condiciones que permitan que las relaciones entre todos los miembros de la sociedad se desarrollen con base en la igualdad jurídica. Con ello, la integración pretende la inclusión social real de los extranjeros sin sacrificar la diversidad. Por lo que, la incorporación del derecho de sufragio constituye una herramienta clave para la integración. Habermas ha propuesto que:

[...] Se relativice la propia forma de existencia atendiendo a las pretensiones legítimas de las demás formas de vida, que se reconozcan iguales derechos a los otros, a los extraños, con toda su idiosincrasia y todo lo que en ellos nos resulta difícil de entender, que uno no se empecine en la universalización de la propia identidad, que no excluya y condene todo cuanto se desvíe de ella (Habermas, 1989, pp.118-119).

Con su teoría del universalismo busca una integración absoluta mediante la entrega de iguales derechos a todos, sin importar su origen o procedencia. Bajo esta premisa, el proceso de integración se convierte en una relación simbiótica que, en su significado más básico, ocurre cuando dos o más individuos se unen beneficiándose unos de otros y sacando siempre provecho de su vida en común. Así, una integración real y efectiva crearía ese vínculo de dependencia mediante el cual todos los miembros de la sociedad obtienen beneficios y todos tienen los mismos derechos y obligaciones, promoviendo y procurando el bien común. Para poder alcanzar ese nivel de integración, el reconocimiento pleno de derechos constituye una medida ideal.

La pertenencia a una sociedad no sólo proviene del vínculo político-jurídico de la nacionalidad sino de un vínculo fundamentalmente social y fáctico que nace y se crea a partir de hechos sociales como el trabajo, la residencia, el asentamiento de la familia y la participación en la vida social y cultural. En consecuencia, la residencia estable en un Estado 
constituye un factor más adecuado para el otorgamiento de este derecho con miras a una integración real en la sociedad de acogida.

Además, desde una perspectiva de derechos humanos, la participación política permite el libre desarrollo de la persona y de su personalidad. La dignidad y la plena realización del individuo se logran a través de su participación en su comunidad. Conviven, trabajan y se desarrollan diariamente con la sociedad de acogida y merecen poder participar plenamente en ella. Si no se garantiza esta posibilidad, se pierde la integración y se genera marginación, división y tensión en de la sociedad de acogida, que no permite a las personas extranjeras desarrollarse libremente y ejercer a plenitud sus derechos humanos.

Es importante mencionar que al estar los derechos humanos interconectados, la única forma de conseguir su pleno ejercicio es que no se queden por fuera parte de los derechos de participación política. La Corte IDH ha manifestado que:

Los derechos políticos son derechos humanos de importancia fundamental dentro del sistema interamericano que se relacionan estrechamente con otros derechos consagrados en la Convención Americana como la libertad de expresión, la libertad de reunión y la libertad de asociación y que, en conjunto, hacen posible el juego democrático (Corte IDH, Castañeda Gutman vs. Estados Unidos Mexicanos, párr. 140).

Por tanto, por su importancia las personas extranjeras merecen gozar de la totalidad del catálogo de derechos políticos.

\section{Estado actual del derecho de sufragio de los extranjeros en el derecho comparado}

Para este estudio se escogió 14 Estados de Europa y América Latina, los cuales constituyen casos interesantes de estudio por el desarrollo o tratamiento que le han dado al derecho de sufragio activo y pasivo de los extranjeros dentro de su ordenamiento jurídico. Se los ha agrupado en 4 subcategorías que recogen los distintos escenarios existentes y que permiten ejemplificar y tener una visión adecuada del estado actual del sufragio de personas extranjeras en el derecho comparado.

\subsection{Estados que reservan el derecho de sufragio sólo a sus nacionales}

\subsubsection{Italia}

Según el Artículo 48.1 de su Constitución "son electores todos los ciudadanos hombres y mujeres que hayan alcanzado la mayoría de edad”. Así mismo, el Artículo 51.1, establece que "todos los ciudadanos de uno y otro sexo podrán desempeñar cargos públicos y puestos electivos en condiciones de igualdad, según los requisitos establecidos por la Ley”. Estos mismos principios están recogidos en su Ley Electoral del 20 de marzo de 1967. Por consiguiente, dado que sólo es ciudadano aquel que tiene la nacionalidad italiana, el derecho de sufragio de los extranjeros está completamente vetado.

La única excepción es la participación de los extranjeros comunitarios en las elecciones municipales, que se incluyó mediante Decreto Legislativo de 12 de abril en 1996, para cumplir con el Tratado de Maastricht.

De momento, sólo se han podido crear cauces alternativos de participación. Así, por ejemplo, en el Ayuntamiento de Roma, en el 2004, se eligieron cuatro representantes extranjeros municipales, uno por cada continente de proveniencia (excepto Europa) y se les dio la facultad de presentar propuestas y demandas en representación de los colectivos inmigrantes (De Lucas y otros, 2008). 


\subsubsection{Alemania}

La Ley Fundamental de Bonn en su Artículo 20.2 dispone que "todo poder del Estado emana del pueblo. Este poder es ejercido por el pueblo mediante elecciones y votaciones y por intermedio de órganos especiales de los poderes legislativo, ejecutivo y judicial" y el Artículo 28.1 añade que "en los Länder, distritos y municipios, el pueblo deberá tener una representación surgida de elecciones generales, directas, libres, iguales y secretas. En los distritos y municipios, de acuerdo con el Derecho de la Comunidad Europea, el derecho de votar y de ser elegido lo tienen también las personas que posean la nacionalidad de un Estado miembro de la Comunidad Europea”.

El texto constitucional alemán cierra completamente cualquier posibilidad de otorgar derechos de participación política a los inmigrantes, por dos razones: 1. La soberanía emana del pueblo integrado por los ciudadanos alemanes, quienes ostentan la nacionalidad sobre la base del más estricto ius sanguinis. 2. Se aclara específicamente que sólo los extranjeros comunitarios tienen derecho a participar en las elecciones locales (Santolaya y Revenga, 2007).

A finales de los ochenta Alemania experimentó dos intentos locales de ampliar los derechos de los extranjeros. En la ciudad-Estado de Hamburgo y en Schelswig-Holstein. En este último, el parlamento reformó su Ley Electoral y atribuyó el derecho de sufragio en las elecciones locales a nacionales de 6 países del entorno que reconocían el mismo derecho a los alemanes. No obstante, el Tribunal Constitucional Federal declaró su inconstitucionalidad, el 31 de octubre de 1990, y declaró que:

La expresión de pueblo como titular del poder que emplea tanto la Ley Fundamental como las constituciones de los Länder en cuestión, implica una restricción al derecho de sufragio únicamente a los plenos ciudadanos alemanes, excluyendo por tanto, que el legislador pueda reconocer el derecho a la participación de los extranjeros en las elecciones locales. El poder del Estado en la República Federal es la emanación de los súbditos alemanes en virtud de la Ley Fundamental y que en consecuencia sólo los alemanes pueden participar en las elecciones aunque sea sólo a nivel municipal (Lozano, 1991, pp. 30-38).

\subsubsection{Francia}

El Artículo 3 de la Constitución Republicana de 1958 dispone que "son electores en las condiciones determinadas por la Ley, todos los ciudadanos franceses mayores de edad, de ambos sexos, que gocen de derechos civiles y políticos"; haciendo imposible la extensión del derecho de sufragio a los extranjeros.

En los años ochenta, a pesar de la clara exclusión constitucional de los extranjeros, dos municipios franceses (Nos en Barouel y Longjumeau) incluyeron tres consejeros municipales con carácter de "asociados" al Consejo Municipal, elegidos directamente por la población extranjera domiciliada dentro del municipio, que podían intervenir con su criterio en asuntos relacionados con la inmigración o en temas de interés para el colectivo inmigrante. No obstante, esta decisión fue declarada nula por el Tribunal Administrativo de Versalles, en 1991.

Cuando se firmó el Tratado de Maastricht, el Consejo Constitucional consideró que el reconocimiento del derecho de sufragio local a los ciudadanos comunitarios era contrario a la Constitución en la medida en que la elección de los consejeros municipales tiene incidencia en la composición del Senado. Por tanto, Francia debió efectuar una reforma constitucional para incluir una excepción respecto a los ciudadanos comunitarios. Actualmente, el Artículo 88.3 señala que: 
[...] de acuerdo con criterios de reciprocidad y del modo previsto por el tratado de la Unión Europa, el derecho de sufragio activo y pasivo en las elecciones municipales sólo podrá concederse a los ciudadanos de la Unión Europea residentes en Francia, quienes no podrán ejercer las funciones de alcalde o teniente de alcalde ni participar en la designación de electores senatoriales ni en la elección de los senadores. Una ley orgánica votada en los mismos términos por las cámaras determinará las condiciones de aplicación del presente artículo.

\subsubsection{México}

La Constitución Política de los Estados Unidos Mexicanos establece en su Artículo 35 que son derechos exclusivos del ciudadano: "I. Votar en las elecciones populares; II. Poder ser votado para todos los cargos de elección popular, teniendo las calidades que establezca la ley”. En cuanto a las obligaciones de los ciudadanos dispone que, entre otras, deberán:

III. Votar en las elecciones y en las consultas populares, en los términos que señale la ley; IV. Desempeñar los cargos de elección popular de la Federación o de los Estados, que en ningún caso serán gratuitos, y V. Desempeñar los cargos concejiles del Municipio donde resida, las funciones electorales y las de jurado.

En consecuencia, dado que el texto constitucional mexicano ha reservado la participación política activa y pasiva exclusivamente a sus nacionales, el sufragio de los extranjeros está completamente vetado.

\subsection{Estados que conceden el derecho de sufragio a determinados extranjeros}

\subsubsection{Reino Unido}

En el Reino Unido el derecho de voto se encuentra reconocido únicamente a los ciudadanos de la Commonwealth por los lazos históricos de unión que comparten. Al tenor de la Ley de 1981, cuando se hace referencia al concepto de ciudadano se incluye, además de a los británicos, a los nacionales de todos los países de la Commonwealth. Así, de acuerdo con la Ley sobre Representación del Pueblo de 2000, pueden votar en todas las elecciones los ciudadanos británicos, irlandeses y los miembros de países pertenecientes a la Commonwealth; siempre que sean mayores de edad, estén censados en una circunscripción electoral y no estén sometidos a ninguna incapacidad legal.

Respecto a las elecciones locales, en virtud de lo dispuesto en el Artículo 2 de la Ley sobre Representación del Pueblo (de 1949 y actualizada en el 2000) los súbditos británicos y los nacionales de Irlanda son electores en la medida que tengan domicilio en un distrito electoral determinado. A estos se suman también, según el Artículo 2 inciso b, todos los ciudadanos comunitarios mayores de edad.

Es preciso señalar que conforme lo dispuesto en la normativa electoral, el ejercicio de este derecho se encuentra sujeto a dos requisitos: La inscripción del extranjero dentro de las listas del censo electoral y la residencia por un periodo amplio de tiempo. Dado que la ley no prevé requisito temporal para registrarse como elector, le corresponde a un juez la apreciación de tal hecho (Arnaldo y otros, 1999).

\subsubsection{España}

El Artículo 13.2 de la Constitución española de 1978 determina que "Solamente los españoles serán titulares de los derechos reconocidos en el Artículo 23, salvo lo que, atendiendo a 
criterios de reciprocidad pueda establecerse por tratado o ley para el derecho de sufragio activo en las elecciones municipales". Complementariamente, el Artículo 23.2 establece que "los ciudadanos tienen el derecho a participar en los asuntos públicos, directamente o por intermedio de representantes; así mismo tienen derecho a acceder en condiciones de igualdad a las funciones y cargos públicos”. Finalmente, el Artículo 68.5 del mismo texto constitucional determina que son "electores y elegibles todos los españoles que estén en pleno uso de sus derechos políticos".

En virtud del contenido literal de la norma constitucional, el derecho de sufragio de los extranjeros es una excepción circunscrita únicamente al ámbito local y al sufragio activo, aplicable sólo para residentes legales bajo criterios de estricta reciprocidad, que deberá estar previsto mediante tratado internacional o ley.

Actualmente, España cuenta con acuerdos bilaterales con países como Argentina, Bolivia, Cabo Verde, Colombia, Uruguay, Venezuela, Chile, Ecuador, Islandia, Noruega, Nueva Zelanda, Paraguay y Perú. Además, por el Tratado de Maastricht, también cuentan con derecho el sufragio activo y pasivo local los ciudadanos europeos.

\subsection{Estados que conceden el derecho de sufragio a todos los extranjeros residentes en el ámbito local}

\subsubsection{Suecia}

La Constitución de 1975, en su Artículo 3, en principio, reserva el derecho de sufragio a sus ciudadanos, pues limita el derecho de sufragio en las elecciones parlamentarias a los nacionales suecos. No obstante, constitucionalmente no se define quien tiene derecho de sufragio en las circunscripciones locales, lo que permitió que, tras una reforma electoral efectuada en 1976, todos los extranjeros puedan participar en las elecciones municipales. A partir de entonces, conforme a su Ley Electoral, tienen derecho de sufragio activo y pasivo en las elecciones municipales todos aquellos extranjeros que tengan residencia legal igual o mayor a tres ańos antes de que se produzcan las elecciones. Posteriormente, con la firma del Tratado de Maastricht, el requisito de residencia mínima fue abolido para los ciudadanos comunitarios y nórdicos.

Pese a que, en principio, la participación de los inmigrantes está limitada a los comicios locales y regionales, la normativa sueca concede al Parlamento la facultad de ampliar, excepcionalmente, el derecho de voto de los extranjeros en ciertos referendos nacionales. Se ha llevado a cabo en dos ocasiones: En las consultas sobre la energía atómica de 1980 y en la consulta sobre la adopción de la moneda única europea (De Lucas y otros, 2008).

La participación de los extranjeros ha supuesto algunos cambios dentro del proceso electoral sueco, pues han debido adaptarlo para que sea comprensible y amigable con los inmigrantes; muestra de ello es que en la actualidad las papeletas de votación son publicadas en cuatro lenguas distintas.

\subsubsection{Dinamarca}

Desde 1849, Dinamarca reconoció derechos políticos a todos los residentes, sin importar su nacionalidad (derechos de expresión, asociación, sindicación y afiliación a los partidos políticos). No obstante, no fue sino hasta 1977 que se efectuó la extensión del derecho de sufragio activo y pasivo a los extranjeros. Su reconocimiento se llevó a cabo en 3 fases: En 1977, otorgó el derecho de voto dentro de las elecciones locales y regionales a los residentes de los países nórdicos. En 1981, se modificó la Ley reguladora de las elecciones municipales (Ley 143, 30 de marzo 1981) y se incluyó el derecho de sufragio local para los inmigrantes 
procedentes del resto de países. Además, se establecieron los requisitos que deben reunir los extranjeros que deseen participar en los comicios locales: Tener mínimo 18 años, estar domiciliados en el respectivo municipio y haber residido en Dinamarca al menos 3 años antes de efectuadas las elecciones. Finalmente, en 1995 se extendió, de manera específica, este derecho a todos los ciudadanos de la Unión Europea y se abolió el requisito de residencia mínima para residentes comunitarios y nórdicos.

Lamentablemente, en la actualidad, Dinamarca se ha distanciado de las tendencias integradoras. A partir del año 2001 las políticas de inmigración se han vuelto cada vez más restrictivas y de manera constante se debate la posibilidad de volver atrás y reservar los derechos políticos a los ciudadanos daneses. Estas propuestas son parte de la agenda de los partidos conservadores, especialmente porque el número de extranjeros con derecho de voto se ha cuadriplicado en los últimos años y estiman que puede constituir un riesgo para la soberanía del Estado.

\subsubsection{Países Bajos}

La Constitución de 1983 incluyó la posibilidad de conceder el derecho de sufragio, tanto activo como pasivo, en las elecciones locales, a todos los extranjeros residentes. Así, su Artículo 130 estipula que el derecho a elegir a los miembros del consejo municipal y el derecho a ser miembro de un consejo municipal deberá ser garantizado a través de una Ley del Parlamento a los residentes extranjeros, siempre que cumplan al menos los requisitos aplicables a los nacionales de los Países Bajos. Para hacer efectivo este precepto, en ese mismo año, se llevó a cabo una reforma al Código Electoral y se estableció que los residentes no nacionalizados pueden participar en las elecciones para el ayuntamiento, siempre que estén jurídicamente establecidos en los Países Bajos por lo menos con cinco años de anterioridad a las elecciones.

Actualmente, la Ley Electoral de 28 de septiembre de 1989 (modificada en 2005) dispone que para que los extranjeros no comunitarios puedan participar como electores o elegibles en las elecciones locales, deberán tener 18 años el día que se celebren las elecciones y ser residentes de la municipalidad correspondiente. Además, deberán contar una residencia legal e ininterrumpida de 5 ańos o ser portadores de un permiso de residencia permanente. El requisito de estancia previa debe ser comprobado ex oficio por las autoridades municipales en el Padrón General de Población.

Las primeras elecciones en las que tuvieron ocasión de participar los extranjeros residentes fueron en 1986 y, aunque su participación no fue elevada, se obtuvieron resultados importantes pues consiguieron un total de 20 consejeros municipales extranjeros (Arnaldo y Rodríguez-Drincourt, 1998). En las últimas décadas su participación se ha incrementado considerablemente; los estudios reflejan que las cifras de participación se han cuadriplicado y que actualmente la mitad de todos los concejales del país son de procedencia extranjera (Moya y Viñas, 2010).

\subsubsection{Argentina}

En la última reforma constitucional se incorporó un capítulo denominado Nuevos Derechos y Garantías, en el cual se incluyó la regulación constitucional de la participación política. En su Artículo 37 se dispuso que:

Esta Constitución garantiza el pleno ejercicio de los derechos políticos, con arreglo al principio de la soberanía popular y de las leyes que se dicten en consecuencia. El sufragio es universal, igual, secreto y obligatorio. La igualdad real de oportunidades entre varones 
y mujeres para el acceso a cargos electivos y partidarios se garantizará por acciones positivas en la regulación de los partidos políticos y en el régimen electoral.

Por lo que a nivel constitucional no existe un impedimento para el sufragio activo de los extranjeros en los procesos electorales. No obstante, a nivel federal, la ley si establece como condición para el ejercicio del derecho de sufragio la ciudadanía; manteniendo reservado este derecho únicamente a los argentinos por nacimiento, por opción o por naturalización. Lo mismo sucede con el sufragio pasivo, ya que la Constitución Federal establece la ciudadanía como requisito para ejercer cargos como presidente, vicepresidente, diputado o senador (Perícola, 2015).

Debido a que Argentina es una República Federal y que sus provincias tienen autonomía para definir sus instituciones locales y elegir a sus autoridades, a nivel provincial y municipal, sí se ha extendido la posibilidad de participación política de los extranjeros residentes. Veinte y dos provincias argentinas reconocen el derecho de sufragio a los extranjeros, aunque en distintos alcances y con diferentes presupuestos y requisitos. Así, por ejemplo, la Provincia de Buenos Aires, mediante Ley No. 11.700 Extranjeros-Régimen Electoral, en su Artículo 1, dispuso que:

Los extranjeros, de ambos sexos, mayores de edad, que sepan leer y escribir en idioma nacional, con dos años de residencia inmediata en el territorio de la provincia de Buenos Aires, podrán ser electores en todos los comicios que se realicen para elegir Gobernador, Vicegobernador, Legisladores Provinciales, Intendentes Municipales, Concejales, Consejeros Escolares y Diputados Constituyentes, así como pronunciarse en todo tipo de consulta popular y en los plebiscitos contemplados en el artículo 206, inciso b de la Constitución de la Provincia.

Asímismo, permite la participación de los extranjeros como candidatos en las elecciones municipales, siempre que tengan más de cinco año de residencia en la provincia y consten inscritos en el registro especial.

\subsubsection{Colombia}

Su Constitución en el Artículo 100 establece que "los derechos políticos se reservan a los nacionales, pero la ley podrá conceder a los extranjeros residentes en Colombia el derecho al voto en las elecciones y consultas populares de carácter municipal o distrital". Así, el derecho de sufragio activo a los extranjeros se otorgó a través de la Ley $\mathrm{N}^{\circ} 1070$ de 31 de julio de 2006. En su Artículo 2 ésta determina que las elecciones en las que podrán participar los extranjeros residentes en Colombia serán las de alcaldes Distritales y Municipales, Concejos Distritales y Municipales, y Juntas Administradoras Locales Distritales y Municipales en todo el territorio Nacional; y, para ejercitar este derecho deberán inscribirse en la Registraduría Nacional del Estado Civil, en los términos fijados por la ley.

\subsection{Estados que conceden el derecho de sufragio a los extranjeros en todos los procesos electorales}

5.4.1. Chile

Conforme al Artículo 14 de su Constitución:

Los extranjeros avecindados en Chile por más de cinco años y que cumplan con los requisitos señalados por el inciso primero del artículo 13, podrán ejercer el derecho de sufragio en los casos y formas que determine la Ley. 
A este efecto, la Ley Orgánica Constitucional de Votaciones Populares y Escrutinios (Ley 18.700) no han incluido ninguna restricción respecto al tipo de elecciones en las que pueden participar los extranjeros. En el Artículo 60 de la Ley se dispone que "son electores, para los efectos de esta Ley, los ciudadanos y extranjeros que figuren con inscripción vigente en los registros electorales".

En cuanto a los requisitos para ejercer el derecho de sufragio, la propia Constitución establece que deberán cumplir los mismos que los ciudadanos chilenos: Haber cumplido 18 años de edad y no haber sido condenados a pena aflictiva (Art. 13). Como complemento, la Ley 18.556 Orgánica Constitucional sobre Sistema de Inscripciones y Servicio Electoral, en su Artículo 2 dispone que los ciudadanos y extranjeros deberán inscribirse en los registros electorales; pudiendo hacerlo los chilenos que cumplan 18 años y los extranjeros que, además de haber cumplido esa edad, hayan estado avecindados en Chile durante al menos cinco ańos y cuenten con el correspondiente certificado del Ministerio del Interior.

\subsubsection{Ecuador}

En Ecuador, desde la aprobación de la Constitución de 2008 no existe distinción alguna entre nacionales y extranjeros a la hora de otorgar los derechos. Así, en su Artículo 9 se establece que las personas extranjeras que se encuentren en el territorio ecuatoriano tendrán los mismos derechos y deberes que las ecuatorianas, de acuerdo con la Constitución.

Concretamente, respecto del derecho de sufragio, el Artículo 62 dispone que "las personas en goce de sus derechos políticos tienen derecho al voto universal, igual, secreto y escrutado públicamente" y el Artículo 63 completa esta disposición al establecer que "las personas extranjeras residentes en el Ecuador tienen derecho al voto siempre que hayan residido legalmente en el país al menos cinco años".

Por su parte, el Código Orgánico de la Democracia determina que el voto de los extranjeros será facultativo y lo podrán ejercer desde los 16 años de edad, para lo cual deberán inscribirse en el Registro Electoral, de conformidad con la normativa que el Consejo Electoral emita para ello.

En cuanto al derecho de sufragio pasivo, el Ecuador también les reconoce este derecho a los extranjeros aunque con ciertas limitaciones. En el Artículo 61 de la Constitución se establece que los extranjeros gozarán de los derechos de participación en lo que les fuere aplicable y veta a los extranjeros únicamente de la posibilidad de ser candidatos a Presidente y Vicepresidente de la República. Además, la norma electoral ecuatoriana establece que para postularse como candidatos los extranjeros deberán cumplir los mismos requisitos que los ecuatorianos y haber vivido en la respectiva jurisdicción al menos dos años de forma ininterrumpida.

\section{Conclusiones}

Pese a ser un importante elemento de la democracia representativa y de la integración, el reconocimiento del derecho de sufragio a personas extranjeras en el derecho comparado sigue siendo parcial y muy limitado. Se ha extendido el derecho de sufragio activo (elegir) pero casi siempre para el ámbito local, pues salvo en Ecuador y Chile las elecciones nacionales corresponden únicamente a nacionales. En el ámbito pasivo en cambio, el sufragio permanece restringido, muy pocos lo otorgan a nivel local e incluso Ecuador lo restringe para el cargo de presidente.

Uno de los factores más influyentes en el nivel de apertura de los Estados hacia el reconocimiento de derechos de los extranjeros tiene que ver con su historia más reciente como receptores o emisores de inmigración. Alemania, Francia o Italia, que han sido grandes 
receptores de inmigración en las últimas décadas, mantienen vetado este derecho a los extranjeros; mientras que Ecuador, emisor y receptor de importantes flujos migratorios, ha reconocido la ciudadanía universal y el derecho de sufragio activo y pasivo.

El derecho de sufragio de personas extranjeras bajo criterio de reciprocidad o pertenecientes a países "amigos" demuestra que la visión del extranjero como potencial enemigo no ha sido superada y por ello se imponen requisitos que brinden confianza.

Pese al cierre normativo, la necesidad de integración y reconocimiento de derechos a las personas extranjeros está presente hasta en los Estados más conservadores, tanto que éstos han debido buscar mecanismos alternativos de participación para la integración de los extranjeros residentes.

Los Estados que permiten el sufragio activo en todos sus procesos electorales son una excepción, pero evidencian la factibilidad de otorgar estos derechos sin riesgos.

A día de hoy no existe un país que otorgue igualdad plena y ciudadanía universal completa, pues incluso en Ecuador, la posibilidad de ser candidato presidencial está vetada a personas extranjeras.

La universalización del sufragio, la legitimidad democrática y la democracia representativa exigen que se incorpore a todos los miembros reales de una sociedad sin importar su nacionalidad, acudiendo a factores más reales como la residencia permanente.

Lamentablemente, las tendencias políticas conservadoras actuales convierten el reconocimiento pleno de derechos de las personas extranjeras en un difícil reto. El endurecimiento en las políticas migratorias, la propensión al cierre de fronteras y los discursos políticos cargados de nacionalismos hacen más dura la lucha por la universalización de los derechos.

\section{Referencias bibliográficas}

Aja, E y Moya, D. (2008). El derecho de sufragio de los extranjeros residentes. En E. Aja, J. Arango y J. Oliver (eds). La inmigración en la encrucijada. Anuario de la inmigración en España. Barcelona: Bellaterra S.L.

Arnaldo, A. y Rodríguez-Drincourt, J. (1998). Una revisión crítica del derecho de sufragio de los extranjeros en las elecciones locales ante la primera aplicación en Espańa. Revista de las Cortes Generales, 1 (45), 185-212.

De Lucas, J. (1994). El desafio de las fronteras. Derechos humanos y xenofobia frente a una sociedad plural. Madrid: Temas de Hoy.

De Lucas, J. et. al. (2008). Los derechos de participación como elemento de integración de los inmigrantes. Bilbao: Fundación BBVA.

Habermas, J. (1989). Identidades nacionales y postnacionales. Madrid: Tecnos.

- (2010). La inclusión del otro: Estudios de teoría política. Barcelona: Paidós.

Kelsen, H. (1977). Esencia y Valor de la democracia. Madrid: Guadamarra.

López, A. (2005). Inmigrantes y Estados: la respuesta politica ante la cuestión migratoria. Barcelona: Anthropos.

Lozano, J. (1991). Derecho de sufragio de los extranjeros en las elecciones locales. Cuadernos de la Escuela Diplomática. Madrid: Escuela Diplomática.

Marshall, T. (2007). Ciudadanía y clase social. Madrid: Alianza Editorial.

Massó, M. (1997). Los derechos políticos de los extranjeros en el Estado nacional. Los derechos de participación politica y el acceso a las funciones públicas. Madrid: Colex. 
Moya, D. y Viñas, A. (2010). Sufragio y participación política de los extranjeros extracomunitarios en Europa. Barcelona: Fundación Carles Pi I Sunyer.

Perícola, M. (2015). El derecho de sufragio de los extranjeros. Pensar en Derecho, 7. Buenos Aires: Editorial Universitaria de Buenos Aires.

Presno, M. (2011). El derecho de voto: un derecho político fundamental. Autopublicación. $<$ https://presnolinera.files.wordpress.com/2011/10/el-derecho-de-voto-un-derecho-polc3adtico-fundamental-libro.pdf >

Ramiro, M. (2008). El derecho de sufragio activo y pasivo de los inmigrantes, una utopía para el siglo XXI. Revista Derechos y Libertades, 2 (18), 97-124.

Rodríguez-Drincourt, J. (1997). Los derechos politicos de los extranjeros. Madrid: Civitas S.A.

Rubio-Marin, R. (2000). Immigration as a democratic challenge. Citizenship and inclusion in Germany and the United States. Inglaterra: Cambridge University Press.

Santolaya, P. (2008). El sufragio de los extranjeros. Un estudio de derecho comparado. Madrid: Centro de Estudios Políticos y Constitucionales.

Santolaya, P. y Revenga, M. (2007). Nacionalidad, extranjería y derecho de sufragio. Madrid: Centro de Estudios Políticos y Constitucionales.

Schmitt, C. (1992). Teoría de la Constitución. Madrid: Alianza Editorial S.A.

Solanes, A. (2008). La participación política de las personas inmigrantes: Cuestiones para el debate. Revista Derechos y Libertades, 2 (18), 67-95.

\section{Sentencias}

Corte IDH (2008) Caso Castañeda Gutman vs. Estados Unidos Mexicanos. Excepciones Preliminares, Fondo, Reparaciones y Costas. Sentencia de 6 de agosto de 2008.

\section{Legislación}

Asamblea Nacional de la República del Ecuador (2008). Constitución de la República del Ecuador. Registro Oficial 449.Ecuador, 20 de octubre de 2008.

- (2009). Código Orgánico de la Democracia. Registro Oficial Suplemento 578, 27 de abril de 2009.

Asamblea Federal de Austria (1920). Constitución de la Primera República de Austria. Austria, 1 de octubre de 1920.

Parlamento de la República de Francia (1958). Constitución de la Quinta República Francesa. 4 de octubre de 1958.

Congreso de los Estados Unidos Mexicanos (1917). Constitución Politica de los Estados Mexicanos. Diario Oficial 30, 5 de febrero de 1917.

Congreso de la República de Colombia (1991). Constitución Política de Colombia. Gaceta Constitucional 116, 20 de julio de 1991.

- (2006). Ley $N^{\circ}$ 1070. Diario Oficial No 46346, 31 de julio de 2006.

Congreso Nacional de Chile (1998). Orgánica Constitucional de Votaciones Populares y Escrutinios de Chile, Ley $N^{\circ}$ 18.700. Diario Oficial No 33.064, 6 de mayo 1988.

- (1986). Orgánica Constitucional sobre Sistema de Inscripciones Electorales y Servicio Electoral de Chile, Ley $N^{\circ}$ 18.556. Diario Oficial No 32.855, 1 de octubre de 1986.

Consejo de Estado Chileno (1980). Constitución Política de la República de Chile. 21 de octubre de 1980.

Cortes Generales (1978). Constitución Española . Boletín Oficial del Estado 311.1, 9 de 
diciembre de 1978.

Estados Generales de los Países Bajos (2000). Constitución del Reino de los Países Bajos. 24 de agosto de 1815, reformada el 2000.

Parlamento Unicameral de Dinamarca (1953). Constitución del Reino de Dinamarca. Boletín Oficial, 5 de junio de 1953.

Parlamento de la República de Italia (1948). Constitución de la República Italiana. Boletín Oficial, 1 de enero de 1948.

Parlamento de la República Federal de Alemania (1949). Ley Fundamental de la República Federal de Alemania. Gaceta Oficial Federal 1, 23 de mayo de 1949.

Parlamento del Reino Unido (1949). Representation of the People Act. 24 noviembre 1949Parlamento Unicameral de Dinamarca (1981). Ley $N^{\circ} 143.30$ de marzo de 1981.

\section{Convenciones, tratados y conferencias}

Asamblea Nacional Constituyente Francesa (1789). Declaración de los Derechos del Hombre y del Ciudadano. Firmada el 26 de agosto de 1789.

Organización de los Estados Americanos (2001). Carta Democrática Interamericana. Firmada el 11 de septiembre de 2001.

Parlamento Europeo (1992). Tratado de Maastricht. Adoptado el 7 de febrero de 1992. 